\title{
o Congresso Nacional e o seu Funcionamento
}

\author{
Prof. Chagas Melo
}

No artigo - O Congresso Nacional e seu fun. cionamento - faz o autor minucioso estudo de hermenêutica legislativa, quanto à tramitação de projetos de lei nas nossas duas Casas do Congresso.

A discriminação de competência dada pela delegação de podêtes, estudada num confronto do Legislativo com o Executivo, e as novas modalidades de maior autonomia, que poderá ser concedida ao Poder Executivo, sem infringência ou diminuição da autoridade de Poder Legislativo, são vistas por Chagas Melo, nesse artigo, de maneira minuciosa e formalizada, nos moldes Regimentais do codicilo que rege as normas de conduta interna das Casa do parlamento Brasileiro. (NOTA DA REDAÇ.̃O)

\section{$\mathrm{O}$}

PODER Legislativo é exercido pelo Congresso Nacional, que se compõe da Câmara dos Deputados e do Senado Federal.

São condições de elegibilidade para o Congresso Nacional: a) ser brasileiro nato ou filho de brasileiro ou brasileira, nascidos no estrangeiro, se os pais estiverem a serviço do Brasil, ou, não o estando, se vierem a residir no pais. Neste caso, atingida a maioridade deverão, para conservar a nacionalidade brasileira, optar por ela, dentro de 4 anos; $b$ ) estar no exercício dos direitos politicos; e c) ter idade superior a 21 anos para a Câmara Federal e 35 para o Senado Federal.

De acôrdo com a Constituição, portanto, os naturalizados não podem ser eleitos para o Congresso Nacional, o que nos parece uma injustiça, devendo, no nosso entender, ser alterada a Constituição em seu artigo 38 , para dar aos naturalizados condições de elegibilidade ao Congresso Nacional.

O Congresso Nacional, embora sendo a soma das duas Casas legislativas, Câmara dos Deputados e Senado Federal, tem atribuições privativas, deliberando em seu conjunto. 
Nos casos de competência privativa do Congresso Nacional a que se refere o artigo 66 da Constituição Federal, as matérias são discutidas nas duas casas separadamente, através de projeto de Decreto Legislativo.

Os assuntos previstos no artigo 65 da Constituição Federal são de competência do Congresso Nacional, dependendo, porém, de sanção do Presidente da República. São deliberados através de projeto de Lei, agindo cada casa leg slativa isoladamente.

O art:go 41 da Constituição estabelece os casos em que a Câmara e o Senado se reunirão em sessão conjunta para:

I - inaugurar a sessão legislativa;

II - elaborar o regimento comum;

III - receber o compromisso do Presidente da República e do Vice-Presidente da República;

IV - deliberar sôbre o veto;

$\mathrm{V}$ - homologar a eleição do Presidente da Repúblca ou elegê-lo assim como o Vice-Presidente, na conformidade dos casos estabelecidos na Emenda Constitucional $\mathrm{n}^{\circ} 9$.

VI - apreciar projetos enviados pelo Executivo nos têrmos do artigo $4^{\circ}$, parágrafo único do Ato Institucional de 9 de abril de 1964 .

O artigo acima citado, an ensejo da votação da Emenda Constitucional, deveria ser alterado para incluir como matéria de decisão conjunta do Congresso Nacional a decretação do estado de sítio, a aprovação ou suspensão de intervenção federal e estado de sítio, quando decretados pelo Presidente da República, a autorização para declarar a guerra e fazer a paz, a aprovação das contas do Presidente da República e atos do Tribunal de Contas, o exame dos projetos de lei delegados ao Executivo e a votação dos projetos considerados urgentes pelo Executivo.

Os assuntos a que nos referimos são de natureza relevante e não podem admit'r delongas em votações separadas nas duas Casas do .Congresso, não permitindo ao Executivo uma ação rápida em defesa das instituições democráticas e da integridade nacional, ou no caso das leis delegadas ao pronto atendimento das reformas essenciais ao progresso econômico e social do país.

O funcionamento em conjunto do Congresso Nacional é dado pelo Regimento Comum que estabelece ainda o ritual para posse do Presidente e Vice-Presidente da República, inauguração da sessão legislativa, deliberação sôbre o veto.

Trata o Regimento Comum dos projetos de lei em revisão, isto é, quando são remetidos de uma casa para outra, pois tanto 
a Câmara e o Senado podem agir como câmara revisora, dentro da competência constitucional estabelecida no artigo 67 da Cons tituição Federal.

A discussão dos projetos de lei de iniciativa do Presidente da República começará na Câmara Federal, bem como os projetos de lei sôbre matéria financeira e de fixação das fôrças armadas que são de iniciativa do Presidente ou da Câmara dos Deputados. Nis demais casos a iniciativa pode partir do Senado $\mathrm{Fe}$ deral, sendo revisora a outra casa legislativa.

Diz o Regimento Comum em seu art. 37 que todo projeto enviado à Câmara revisora terá uma ementa e será acompanhado de todos os elementos informativos, inclusive mensagens, documentos, processos e avulsos como a proposição, pareceres, substitutivos, emendas e demais elementos informativos. E' lícito à Câmara revisora, sem alterar a ementa, escoimá-la das simples imperfeições de redação, independentes da aprovação da Câmara iniciadora.

Sempre que a Câmara revisora devolver à Câmara iniciadora o projeto com emendas, a Comissão ou as Comissões da última que tiverem de opinar a respeito, oficiarão à revisora, comunicando-lhe, com o minimo de cinco dias, a sessão em que discutirão a matéria.

Ao votar as emendas oferecidas pela Câmara revisora, só é lícito à Câmara iniciadora cindi-las quando se tratar de artigos, parágrafos, alíneas e itens fàcilmente separáveis e desde que não modifiquem ou prejudiquem o sentido da ementa.

A Câmara que ultimar a elaboração do Projeto de Lei votará a sua redação final que será submetido à sanção.

Estabelece ainda o Regimento comum que, quando houver projeto igual em cada uma das Câmaras, terá prioridade, para discussão e votação, o que primeiro chegar à revisão.

Um dos aspectos focalizados como idéia nova é o da Delegação de Podêres, em têrmos compatíveis com o sistema presidencial de Govêrno.

Comentando o assunto, dizem os juristas Santiago Dantas, Carlos Medeiros Silva, Antônio Gonçalves de Oliveira, Brochado da Rocha e Hermes Lima que a Comissão por êles formada acredita "haver estabelecido uma nova modalidade de colaboração entre o Executivo e o Legislativo na feitura das leis. Atualmente, fixadas no texto constitucional, só há duas modalidades nessa colaboração: a iniciativa do Presidente e o veto. Dado, porém, o caráter da legislação moderna destinada a regular a vida de uma sociedade, como a nossa, que cresce e se industrializa a olhos vistos, a possibilidade de autorizar o Legislativo a que o Executivo elabora projetos definitivos da Lei, representa ajuda ines- 
timável, pois entrosa a experiência e o aparelhamento do Govêrno com as atribuições específicas e soberanas do Congresso.

Êsse entrosamento representa na prática a conjugação de Podêres que, sendo independentes, são igualmente harmônicos (art. 36 da Constituição). Independência e harmonia são faces simultâneas da mesma realidade politica. Fazer que elas se realizem concretamente, e através de um processo rápido, em benefício do bem público, foi o pensamento da Comissão. Pensa a Comissão havê-lo alcançado, superando nesse objetivo a questão da delegação de podêres como é posta em seus têrmos estritos.

Entende a Comissão que a prática das delegações legislativas é normal nos regimes presidenciais, inclusive no americano e no nosso. Trata-se de delegações de colaboração, e não de delegações-renúncias. Nem nos Estados Unidos, nem entre nós, jamais se entendeu que uma delegação legislativa confundiria podêres que, por sua natureza, são constitucionalmente distintos. Nos Estados Unidos, a prática das delegações é quase tão velha quanto a Constituição. No famoso caso Hampton (J. W. Hampton, Jr. \& Company, v. United States, 1928) a Suprema Côrte, num julgado de que foi relator o Chief-Justice Taft, esclareceu: "Não quer isto dizer (referia-se à separação de podêres) que os três ramos não sejam partes coordenadas do mesmo govêrno e que cada qual dêles, no campo de suas atribuições, não possa invocar a ação dos demais ramos até onde a ação invocada não constitua invasão da área constitucional de outro ramo. $\mathrm{Na}$ determinação do que é permitido fazer ao buscar a ajuda de outro ramo, a extenssão e o caráter da ajuda devem ser fixados de acôrdo com o senso comum e a inerente necessidade da coordenação govrnamental".

$\mathrm{Na}$ delegação exprime-se, antes de tudo, a inevitabilidade de colaboração entre Legislativo e Executivo, através de formas que o rigor lógico abstrato das interpretações doutrinárias desconhece, mas a experiência impõe. Eis por que são tantos, entre nós, os constitucionalistas, publicistas, jurisconsultos e homens públicos que proclamam o inelutável das delegações e sua conveniência.

Apesar de suas reservas teóricas à prática das delegações no sistema presidencial, admitia-as Rui Barbosa sob o aspecto dos regulamentos delegados.

Em recente conferência, Seabra Fagundes assinalou que a Ação do Poder Executivo na feitura das leis tem sido admitida por todos os povos. "A delegação é mais comum sob o regime parlamentar, porém nada impede, porque tudo é uma criação do legislador constituinte, que, convindo à prática do regime presidencial, sob êsse seja ela admitida. No campo das instituições politicas o que vale primordialmente é a funcionalidade, é a efi- 
ciência, é a utilidade das fórmulas na sua transplantação à realidade ambiente e não a harmonia das regras com modelos teóricos".

Depoimentos antigos e modernos sôbre as vantagens das delegações não faltam em nossa literatura politica. Defenderamnas na Constituinte de 1946, entre outros, Agamemnon Magalhães e Barbosa Lima Sobrinho. Na atualidade, o Deputado Afonso Arinos, discorrendo da Tribuna da Câmara sôbre o assunto, assim se pronunciou: "Tanto o presidencialismo como o parlamentaris mo clássico sofreram ùlt mamente consideráveis adaptações de estrutura, forçados pelo problema do trabalho. A delegação de podêres legislativos é a mais importante destas adaptações. Ainda quando formalmente negada, como em um dos mais infelizes dispositivos de nossa Constituição, é o resultado da pressão invencível do fato econômico sôbre o direito público".

Não pensa de modo diverso o deputado Bilac Pinto, que enumera, entre as causas diretas do desenvolvimento da delegação legislativa, a modificação das condições econômicas que determinaram a extensão do contrôle governamental a setores sociais e industriais da maior complexidade no mundo moderno.

A voz dêsses dois eminentes parlamentares z professôres junta-se a de Temistocles Cavalcanti, ao ponderar "que a falta de delegação de podêres, que é vedada pela Constituição de maneira expressa, constitui, assim, a crítica que pode ser feita ao nosso mecanismo normativo porque é um retardamente na evolução do sistema legislativo".

Além disto, conclui Temístocles Cavalcanti, "há um sem número de leis de natureza técnica que exigem certo número de normas que só podem ser elaboradas por especialistas e que são deformadas na elaboração por um órgão tão numeroso como o Congresso Nacional" (O Sistema Constitucional Brasileiro, no volume Quatro Estudos, pág. 46, publicação do Instituto de Direito Público e Ciência Politica).

Também o eminente. Pontes de Miranda reconhece a inevitabilidade das delegações legislativas. Pensa do mesmo modo João Mangabeira, cuja autoridade é impar no campo do nosso direito público e constitucional. (Página 26 de "Reforma Constitucional", publicação do Ministério da Justiça e Negócios Interiores, Departamento de Imprensa Nacional - Rio de Janeiro - 1956). 